\title{
HEIDEGGER Y LA ECOLOGÍA PROFUNDA
}

\author{
Belén Castellanos \\ IES Práxedes Mateo Sagasti, Logroño
}

\begin{abstract}
Resumen.- Con este artículo tratamos de mostrar el potencial no explotado de la filosofía heideggeriana como basamento teórico para el movimiento ecologista. Nos hemos interesado, sobre todo, por una de las corrientes ecologistas, conocidas como Ecología Profunda, de la cual Arne Naess sería el principal representante. Para acercarnos a su pensamiento hemos utilizado la difusión que de él ha hecho en castellano Andrea Speranza.
\end{abstract}

Palabras clave.- ecologismo, ecología profunda, ontología ecológica, Heidegger

\begin{abstract}
In this article we try to show the untapped potential of Heidegger's philosophy as a theoretical basis for the environmental movement. We focus mainly on the environmental current known as Deep Ecology, from which Arne Naess would be the main representative. To get closer to his thinking we have used the diffusion of his work done in Spanish by Andrea Speranza.
\end{abstract}

Keywords.- environmentalism, deep ecology, ecological ontology, Heidegger

Si hay un ámbito de reflexión ético-política en el que el Romanticismo superó al pensamiento ilustrado, poniéndolo incluso en entredicho, desde sus más básicos pilares, ese es el movimiento ecologista, un movimiento social, de carácter teórico-práctico, y que trata una problemática de primer orden para nuestros días. Si el Romanticismo supuso, en cierto modo, una crítica (o autocrítica) de la metafísica moderna, es porque se atrevió, tempranamente, a cuestionar una de las ideas que han resultado ser más tramposas, dogmáticas y violentas, si atendemos a su correlato práctico. Nos referimos a la idea de Progreso. Los indios de América sufrieron la idea de progreso hasta la exterminación. Diversos colectivos sufrieron la idea de progreso hasta la eugenesia. Dificilmente podemos sacudirnos tales excesos considerándolos asuntos del pasado y menos aún en un momento de implacable globalización como el que vivimos. Pero si hay "alguien" que, indudablemente, sigue sufriendo la idea de progreso, es la Naturaleza: la naturaleza que nos rodea y la naturaleza que nosotros mismos somos.

La modernidad en general y la llustración en particular supusieron una lucha infatigable contra la naturaleza, que a menudo se concebía como una amenaza (o como un resto) para la civilización, como barbarie, como peligrosa voluptuosidad a suprimir o, al menos, a domesticar. La libertad humana parecía estar condicionada por la expulsión de toda realidad no reductible a los esquemas de control y dominación humanos. La naturaleza, las pulsiones, lo inconsciente, lo extranjero y todo lo inconmensurable, fueron tachados de 
violentos, y se levantó toda una maquinaria de violencia organizada contra aquella violencia más primaria e inocente.

Desde la Revolución Industrial hasta nuestros días se han sucedido un buen número de planteamientos ecologistas diferentes y, en ocasiones, incluso divergentes. Partiendo de los primeros conservacionistas y pasando por el mero higienismo, hemos llegado, en los últimos tiempos, a una eclosión de éticas ecológicas, desde las más superficiales hasta las más radicales; desde las más complacientes con el actual sistema económico hasta aquellas que, desde la problemática medioambiental, han considerado necesario cuestionar nuestro modelo de acumulación capitalista, así como la jerarquía de valores que le es propia.

De entre todas estas corrientes nos resulta de especial interés la denominada Ecología Profunda. La Ecología Profunda trata de retroceder a lo más básico o radical, para fundamentar la práxis ecológica ontológicamente, ligándose así a la cuestión de la diferencia ontológica entre naturaleza constituyente o naturaleza entendida desde su carácter embrionario y productivo, y naturaleza constituida, es decir, reducida a esquemas antropocéntricos de conveniencia y explotación humana; pero también al asunto político de la desigualdad económico-social y de la sobreproducción capitalista que ha conducido a la crisis ecológica y medioambiental. Dentro de la elaboración filosófica de la Ecología Profunda, encontramos a pensadores como Arne Naess, que reivindica la vida bajo un presupuesto ampliamente democrático, es decir, en todas sus manifestaciones, y que supone, como condición de posibilidad del respeto generalizado hacia la vida, un cambio profundo del modelo económico vigente. Desde su perspectiva, el respeto a la vida no debe estar limitado por jerarquías o grados. Conviene aclarar que no se trata de una visión netamente antihumanista sino, principalmente, antiantropocéntrista, que presupone una profunda interconexión de los entes naturales, de tal modo que un respeto generalizado hacia ellos abriría, además las posibilidades de autorrealización humanas y de crecimiento personal, prendidas a la capacidad para elaborar cosmovisiones menos dicotómicas y a la capacidad consiguiente para desarrollar contagios empáticos más amplios. Se trata, pues, de una ecología posthumanista que parte de la crítica al antrpocentrismo metafísico y axiológico, para defender algo así como el "derecho de la Tierra", más allá de la mera sostenibilidad para la vida humana.

Dentro de la corriente de la Ecología Profunda, ha sido más que habitual buscar un basamento ontológico en la obra de Spinoza, en la que el hombre aparece como un integrante más de la naturaleza, sin ningún tipo de privilegio ontológico: Desde el punto de vista del Ser, el ser humano no es ni más ni menos que cualquier otra entidad: un hombre, un pájaro, una montaña..., en cuanto que existen se igualan, es decir, no existen unos más que otros. Su derecho a la existencia se igualaría a su perseverancia en el Ser, es decir, a su deseo de preservarse. Sin embargo, Naess no parece tener en cuenta las limitaciones de la filosofía spinozista en cuanto al proyecto teórico ecologista. Si decimos esto es porque, si bien para Spinoza no hay ningún primado ontológico del ser humano, en el ámbito de la ética, éste sería el único sujeto practicante y receptor de la misma. Como fue frecuente en la politología barroca, Spinoza consideraba que el derecho del hombre es el derecho natural, identificándose el derecho natural con la potencia propia de cada ente. Así, la propuesta spinozista era la de tratarse con la naturaleza "en términos naturales", es decir, no normativos. Por ejemplo, aunque Spinoza rebatía la absueda idea cartesiana, según la cual se negaba la sensibilidad de los animales, es decir, su capacidad para experimentar placer y dolor, no concedía, sin embargo, a tal sensibilidad, consideración ética alguna: "... la regla según la cual hemos de buscar nuestra utilidad 
nos enseña, sin duda, la necesidad de unirnos a los hombres, pero no a las bestias o a las cosas cuya naturaleza es distinta de la humana. Sobre ellas, tenemos el mismo derecho que ellas tienen sobre nosotros, o mejor aún, puesto que el derecho de cada cual se define por su virtud, o sea, por su poder, resulta que los hombres tienen mucho mayor derecho sobre los animales que éstos sobre los hombres. Y no es que niegue que los animales sientan, lo que niego es que esa consideración nos impida mirar por nuestra utilidad, usar de ellos como nos apetezca y tratarlos según más nos convenga, supuesto que no concuerdan con nosotros en naturaleza, y que sus afectos son por naturaleza distintos de los humanos"1.

En este punto, la Ecología Profunda echa mano de otros planteamientos políticos, refiriéndose en especial a Gandhi, para rescatar, con él, el valor inherente a las distintas entidades de la Naturaleza, independientemente de su utilidad para propósitos humanos. La diversidad, es decir, la multitud y proliferación de manifestaciones distintas de vida también tendrían un valor en sí mismas. Lo que se defiende, por tanto, es un comportamiento lo menos invasivo posible del ser humano sobre la naturaleza salvaje, dentro, obviamente del requerido para satisfacer las necesidades del ser humano.

Algunas de las propuestas serían:

- la disminución substancial de la población humana;

- la superación de este sistema económico basado en el incremento constante de la producción, de la acumulación y del consumismo;

- la toma de conciencia del carácter relacional de la identidad humana respecto del entorno con el que interactúa;

- el tratamiento crítico de conceptos de la metafísica occidental como son las ideas de Mundo, de Libertad o de Progreso;

- el desarrollo de planes de acción y decisión ecosóficamente fundamentados y compatibles con la diversidad cultural;

- el reajuste en nuestras expectativas vitales partiendo de la idea de que las relaciones (las interacciones humano-humano y humano-naturaleza) son anteriores a los términos y de hecho, los configuran;

- la profundización en las tecnologías del yo en base a la identificación con los otros y con lo otro, ampliando así sus potencialidades": "Al sentir como propias las necesidades de aquellos que más difieren de nosotros, más se expande nuestro yo. De este modo se produce un despliegue que nos conduce a una experiencia de profunda unidad con el resto de la vida"3; "Si las individualidades son manifestaciones de una unidad ontológica subyacente (...), entonces la posibilidad de avanzar en la autorrealización va a estar íntimamente conectada con la autorrealización de "otros", porque todos constituimos una misma unidad. Aquellos estilos de vida que presuponen el éxito o la realización sobre la base de algún tipo de imposición o aniquilación de otros no son más que perversos espejismos. Solamente avanzamos en nuestro proceso de autorrealización cuando el resto de los seres también se realiza"

- El desarrollo de una estética ecológica previa y constituyente de la ética ecológica, dando el primado a la acción bella sobre la acción buena y una mayor importancia a la modificación en los modos de sentir que a la modificación, considerada secundaria, de

\footnotetext{
${ }^{1}$ B. Spinoza: Ética. Op. Cit. Parte IV, prop. XXXVII, Escolio. pp. 290-291.

${ }^{2}$ Usando conceptos de Gilles Deleuze, podríamos decir que el enriquecimiento personal no se produce cuando dejamos nuestra huella por todo el mundo sino cuando dejo que el mundo se dibuje sobre mí.

${ }^{3}$ A. Speranza: Ecología profunda y autorrealización. Ed. Biblos, Buenos Aires, 2006. p. 62.

${ }^{4}$ Ibid. p. 69.
} 
los modos de razonar, reubicando el discurso ético: "John Rodman, por ejemplo, hace referencia a una "sensibilidad ecológica" plasmada en un patrón de percepciones, actitudes y juicios que, de ser adecuadamente desarrollados, constituirían un dispositivo de conductas adecuadas $y$, por consiguiente, hablar en términos de derechos, obligaciones, etc., sería innecesario";

- el desarrollo de proyectos prácticos de autosuficiencia local, que permite, con mayor eficacia, la diversidad natural y cultural;

- la insistencia en las relaciones ecológicas de mutuo beneficio, como las simbióticas;

- el primado del incremento de la calidad devida sobre el incremento en el producto interior bruto, como paradigma de desarrollo.

Para apoyar teóricamente dichas propuestas, Arne Naess, como señalábamos, utiliza los planteamiento gandhianos. Sin embargo, sería conveniente notar que dichos planteamientos dependen en gran medida de presupuestos religiosos. En su lugar proponemos rescatar la obre de un gran pensador del s. XX: Martin Heidegger. Su potencial teórico aún no ha sido explotado por los seguidores de la Ecología Profunda. Por ello, intentaremos aquí esclarecer algunas zonas puntuales de su obra que nos permitirían contribuir a la fundamentación ontológico-política del ecologismo.

La obra de Heidegger supone una crítica de la razón capitalista y de la idea de Progreso adscrita a su modo de pensamiento. El mundo moderno trató de anclar esa idea de Progreso en los presupuestos teoréticos del nacimiento de occidente. Para ello, malinterpretó a menudo el significado del telos griego, entendiéndolo como meta y confundiendo el desarrollo moral con el desarrollo técnico. Sin embargo, el telos, explica Heidegger, es la responsabilidad, no en el sentido moral sino en el sentido que fue inicial, es decir, en el sentido productivo, de causalidad, de llevar algo a aparecer, de dejar venir al advenimiento, de desocultamiento, de aquello de lo que la materia y el aspecto del utensilio sacrificial son responsables. Uno de los modos del salir de lo oculto es la técnica. La técnica apunta hacia el aseguramiento, convirtiendo los objetos en existencias: "El hacer salir de lo oculto que prevalece en la técnica moderna es una provocación que pone ante la Naturaleza la exigencia de suministrar energía que como tal pueda ser extraída y almacenada"6. De esta manera, "la energía oculta de la Naturaleza es sacada a la luz, a lo sacado a la luz se lo transforma, lo transformado es almacenado, a lo almacenado a su vez se lo distribuye, y lo distribuido es nuevamente conmutado"'. La técnica tal y como ahora la entendemos, la tecnología tiene el espíritu de las ciencias de la época moderna, que presentan a la Naturaleza como un entramado de fuerzas calculables ${ }^{8}$. Heidegger no se opone a este modo de ver sino al imperialismo del mismo que impediría el avistamiento de cualquier otra forma de acontecer la verdad, provocando más que un desvelamiento, un velamiento: "El representar científico no es capaz nunca de cercar la esencia de la Naturaleza, porque, de antemano, la obstancia de la Naturaleza es sólo un modo como la Naturaleza se pone en evidencia"'.

Cuando la técnica, así entendida, monopoliza todo el discurso de verdad el ser humano se convierte en mero animal trabajador y desde la perspectiva de trabajador, reduce todo ente natural a objeto destinado a convertirse en existencia, en mercancía. De este modo,

\footnotetext{
${ }^{5}$ Ibid. p. 84-85.

${ }^{6} \mathrm{M}$. Heidegger: Conferencias y artículos. Ed. del Serval. Barcelona, 2001. p. 15.

${ }^{7}$ Ibid. p. 17.

${ }^{8}$ Ibid. p. 26.

${ }^{9}$ Ibid. p. 45.
} 
aún cuando se cree todopoderoso, se aliena él mismo, ya que acaba por convertirse en una pieza más del aparato de producción: En este proceso, en el que la causalidad se reduce a asegurar existencias, también el ser humano se convierte en existencia: "Desde el momento en el que lo no oculto aborda al hombre, no ya siquiera como objeto sino exclusivamente como existencias, y desde el momento en que el hombre, dentro de los límites de lo no objetual, es ya sólo el solicitador de existenciad, entonces el hombre anda al borde de despeñarse, de precipitarse allí donde él mismo va a ser tomado sólo como existencia. Sin embargo, precisamente este hombre que está amenazado así se pavonea tomando la figura del señor de la tierra. Con ello se expande la apariencia de que todo cuanto sale al paso existe sólo en la medida en que es un artefacto del hombre. Esta apariencia hace madurar una última apariencia engañosa. Según ella parece como si el hombre, en todas partes, no se encontrara más que consigo mismo (...) Sin embargo, la verdad es que hoy el hombre no se encuentra en ninguna parte consigo mismo, es decir, con su esencia"10; "El animal trabajador está abandonado al vértigo de sus artefactos, para que de este modo se desgarre a sí mismo y se aniquile en la nulidad de la nada"11.

Marx señalaba que el capitalismo colocaba su razón de ser en la producción y en la elevación constante de ésta. Marx criticaba, a partir de esta idea, el supuesto liberal según el cual, el capital produce únicamente lo que el mercado demanda. Al contrario, el modelo capitalista necesitaría, para mantenerse, seducir una y otra vez a los consumidores con un creciente número de productos, de los cuales se hagan dependientes, mediante las exigencias laborales, entre otras cosas. Al consumo desaforado que el capitalismo necesita generar, Heidegger lo denomina voluntad de voluntad, que constituye, al fin y al cabo, la ausencia de metas finales y la conversión de todo querer en un querer-medio. La voluntad de voluntad valdría por lo que Deleuze denominó más adelante "axiomática capitalista", en la que todo tiende a hundirse en una inmanencia mercantil, como ya anunciaba Marx al afirmar que todo ente deviene mercancía en el Capital. Veámoslo en palabras heideggerianas: "La voluntad de voluntad pone como condiciones de su posibilidad el aseguramiento de las existencias (verdad) y la transferibilidad de las pulsiones (arte). En consecuencia, la voluntad de voluntad, como ser, organiza ella misma el ente. Es solamente en la voluntad de voluntad donde la técnica (el aseguramiento de las existencias) y la ausencia incondicionada de toda meditación (...) acaban dominando"12. "La voluntad de voluntad se impone como formas fundamentales de su aparecer el cálculo y la organización de todo, pero esto sólo para asegurarse a sí misma, de tal forma que pueda seguir de un modo incondicionado"13.

A la conversión de todo ente natural en mercancía, preparada para ser consumida incansablemente por el ser humano, lo denomina Heidegger usura: "El consumo del ente, como tal y en su decurso, está determinado por el equipamiento en el sentido metafísico, algo por medio de lo cual el hombre se hace "señor" de lo "elemental". El consumo incluye el uso reglado del ente, que se convierte en oportunidad y materia para realizaciones $y$ para la intensificación de éstas. Este uso se utiliza en beneficio del equipamiento. Pero en la medida en que éste va a parar a la incondicionalidad de la intensificación y del aseguramiento de sí y tiene realmente como meta la ausencia de metas, este uso es usura"14.

\footnotetext{
${ }^{10}$ Ibid. p. 25.

${ }^{11}$ Ibid. p. 53.

${ }^{12}$ Ibid. p. 63.

${ }^{13}$ Ibid. p. 58.

${ }^{14}$ Ibid. p. 67.
} 
Como decíamos anteriormente, en este proceso, el propio ser humano se aliena, dado que él mismo es el instrumento fundamental: "El hombre es la "materia prima más importante" porque permanece como el sujeto de toda usura, y además de tal forma que, de un modo incondicionado, deja que su voluntad se disuelva en este proceso y con ello se convierte en "objeto" del estado del estado de abandono del Ser"15; "Se pierde la autonomía del sí mismo más propio en la arbitrariedad y azarosidad de las carencias y estímulos que hay que satisfacer de inmediato"16; "Pero un tender tal es tanto más capcioso cuanto que conlleva la apariencia de ser, al cabo, energía para actuar, vitalidad y variedad de facetas"17. Vemos como Heidegger denuncia la captura que la maquinaria capitalista hace de la capacidad deseante de las personas. Si bien en el Deseo encontrábamos el impulso para la realización de proyectos de cognoscitivos y políticos alternativos, el capitalismo ha conseguido ligar el deseo humano a un sentimiento permanente de carancia, impulsándolo así a la repetición de la operación de recambio: "Dondequiera que falte ente -y para la voluntad de voluntad que se afirma cada vez más siempre falta- la técnica tiene que salir al quite recambiando lo que falta y consumiendo materia prima. Pero en realidad el "recambio" y la producción en masa de estas piezas de recambio no son un recurso pasajero sino la única forma posible como la voluntad de voluntad, el aseguramiento total "sin fisuras" del ordenamiento del orden, se mantiene en marcha y de este modo puede ser "ella misma" como "sujeto" de todo. El crecimiento del número de masa humanas se impulsa intencionadamente por medio de planificaciones, para que nunca falte la ocasión de reclamar mayores "espacios vitales" para las grandes masas, espacios que, por su magnitud, exigirán a su vez, para su instalación, masas humanas que consecuentemente serán mayores. Este movimiento circular de la usura por mor del consumo es el único proceso que distingue la historia de un mundo que se ha convertido en in-mundo. "Dirigentes natos" son aquellos que, por la seguridad de su instinto, se dejan enrolar en este proceso como sus órganos de dirección. Son los primeros empleados en el negocio de la usura incondicionada del ente al servicio del aseguramiento del vacío del abandono del Ser"18.

Para Heidegger, el capitalismo sería el nihilismo más acabado. Notemos como en Heidegger la crítica del capitalismo se hace desde el ecologismo y el ecologismo desde la reivindicación de la ontología, es decir, desde la reivindicación del pensar del Ser, que sería lo que por excelencia compete al pensar humano: "En la época del poder exclusivo del poder, es decir, del acoso incondicionado del ente para el consumo en la usura, el mundo se ha convertido en in-mundo, en la medida en que el Ser, si bien esencia, lo hace sin su propio prevalecimiento"19. Así, el sistema capitalista consumaría el olvido del Ser, tantas veces denunciado por Heidegger, alienando al ser humano y aniquilando la filosofía: "... para el interés de hoy vale sólo lo interesante. Esto es aquello que permite estar ya indiferente en el momento siguiente y pasar a estar liberado por otra cosa que lo concierne a uno tan poco como la anterior"20.

El ecologismo de Heidegger se presenta como crítica de la metafísica y de la llustración, y principio de una verdadera ontología. Se trata de un claro agenciamiento del logos de Heráclito que es el Pensar del Ser: "La imperceptible ley de la tierra guarda a ésta en la

\footnotetext{
${ }^{15}$ Ibid. p. 67-68.

${ }^{16}$ Ibid. p. 203.

${ }^{17}$ Ibid. p. 204.

${ }^{18}$ Ibid. p. 70.

${ }^{19}$ Ibid. p. 68.

${ }^{20}$ Ibid. p. 96.
} 
sobriedad que se contenta con el emerger y desaparecer de todas las cosas en el medido círculo de lo posible, al que todo se conforma y al que, no obstante, nada conoce. El abedul no va nunca más allá de aquello que para él es posible. El pueblo de las abejas habita en lo que le es posible. Sólo la voluntad, que por todos lados se instala en la técnica, zamarrea la tierra entregándola, usándola abusivamente y cambiándola en lo artificial. Obliga a la tierra a ir más allá del círculo de lo posible, tal como ha crecido en torno a ella, la obliga a aquello que ya no es posible y por tanto es imposible. El hecho de que los proyectos de la técnica y las medidas que toma ésta consigan muchas cosas en lo referente a inventos y novedades que se persiguen los unos a los otros no es en modo alguno la prueba de que los logros de la técnica hagan posible lo imposible (...) Una cosa es sacar simplemente provecho de la tierra, otra acoger la bendición de la tierra y hacerse la casa en la ley de este acogimiento con el fin de guardar el misterio del Ser y velar por la inviolabilidad de lo posible"21.

También podemos encontrar en Heidegger basamento teórico para la crítica de la globalización y anclar en ella, los proyectos localistas de abastecimiento de la Ecología Profunda: "La uniformidad incondicionada de todas las humanidades de la tierra bajo el dominio de la voluntad de voluntad explica el sinsentido de la actuación humana puesta como absoluto"22.

La crítica a la llustración se hace desde Nietzsche y desde la defensa de la naturaleza, incluida su violencia primaria, aquella contra la que el hombre de la llustración se había levantado: "Pero ¿cómo podrá el hombre acceder al dominio sobre la tierra, cómo puede tomar en su custodia a la tierra como tierra si rebaja, y mientras rebaje, lo terrenal, en la medida en que el espíritu de venganza determina su reflexión? Si hay que salvar a la tierra como tierra, entonces primero tiene que desaparecer el espíritu de venganza"23; "Salvar la tierra es más que explotarla o incluso entregarla. Salvar la tierra no es adueñarse de la tierra, no es hacerla nuestro súbdito, de donde sólo un paso lleva a la explotación sin límites"24; "Los mortales habitan en la medida en que reciben el cielo como cielo. Dejan al sol y a la luna seguir su viaje; a las estrellas su ruta; a las estaciones del año, su bendición y su injuria; no hacen de la noche día ni del día una carrera sin reposo" ${ }^{25}$. Y es que el Ser no es un producto del hombre sino que aquello desde lo que el ser humano experimenta, piensa y es. Así, el olvido del Ser es el olvido del Pensar, es el olvido de lo que condiciona nuestra esencia. En este punto, Heidegger vuelve sobre la importancia del concepto marxista de alienación, invitando así a repensar la historia, volviendo al verdadero telos humano que proponían los griegos: "Es precisamente porque al experimentar el extrañamiento Marx se adentra en una dimensión esencial de la historia por lo que la consideración marxista de la historia es superior al resto de las historias" ${ }^{26}$. Así reubicaríamos la esencia humana, situándola, no ya en el imperio de la técnica y en el nihilismo progresista, sino en el recojimiento por el que pensamos en el Ser, en la inmanente espiritualidad de la Naturaleza.

\footnotetext{
${ }^{21}$ Ibid. p. 72.

${ }^{22}$ Ibid. pp. 72-73.

${ }^{23}$ Ibid. p. 86.

${ }^{24}$ Ibid. p. 111.

${ }^{25}$ Ibid. p. 150.

${ }^{26}$ M. Heidegger: Carta sobre el humanismo. Ed. Alianza, Madrid, 2000. p. 53.
} 


\section{Bibliografía:}

A. Speranza: Ecología profunda y autorrealización. Ed. Biblos, Buenos Aires, 2006. M. Heidegger: Carta sobre el humanismo. Ed. Alianza, Madrid, 2000.

M. Heidegger: Conferencias y artículos. Ed. del Serval. Barcelona, 2001. 